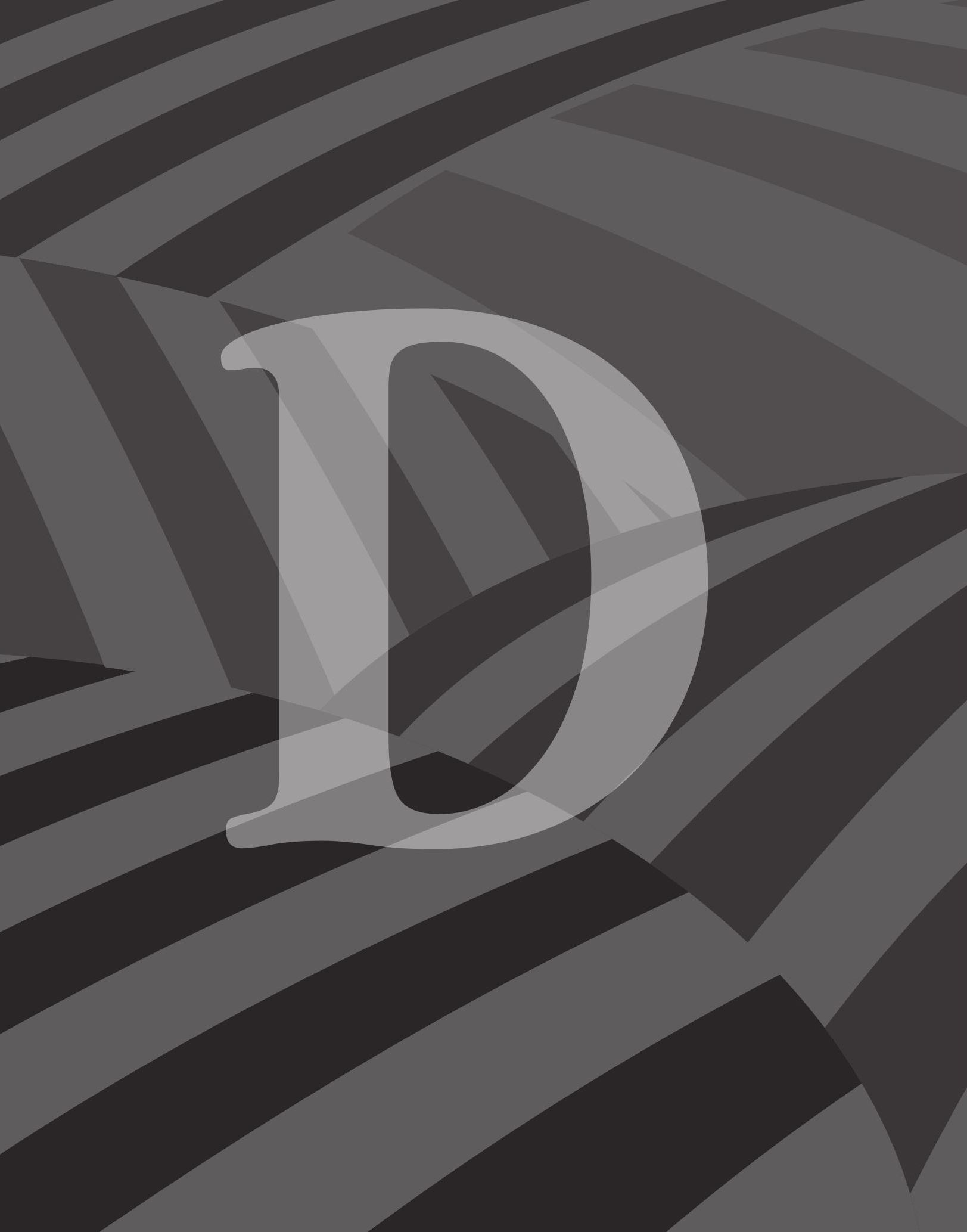


Desafíos en la educación rural-campesina: experiencias, posibilidades y transformaciones para la paz 


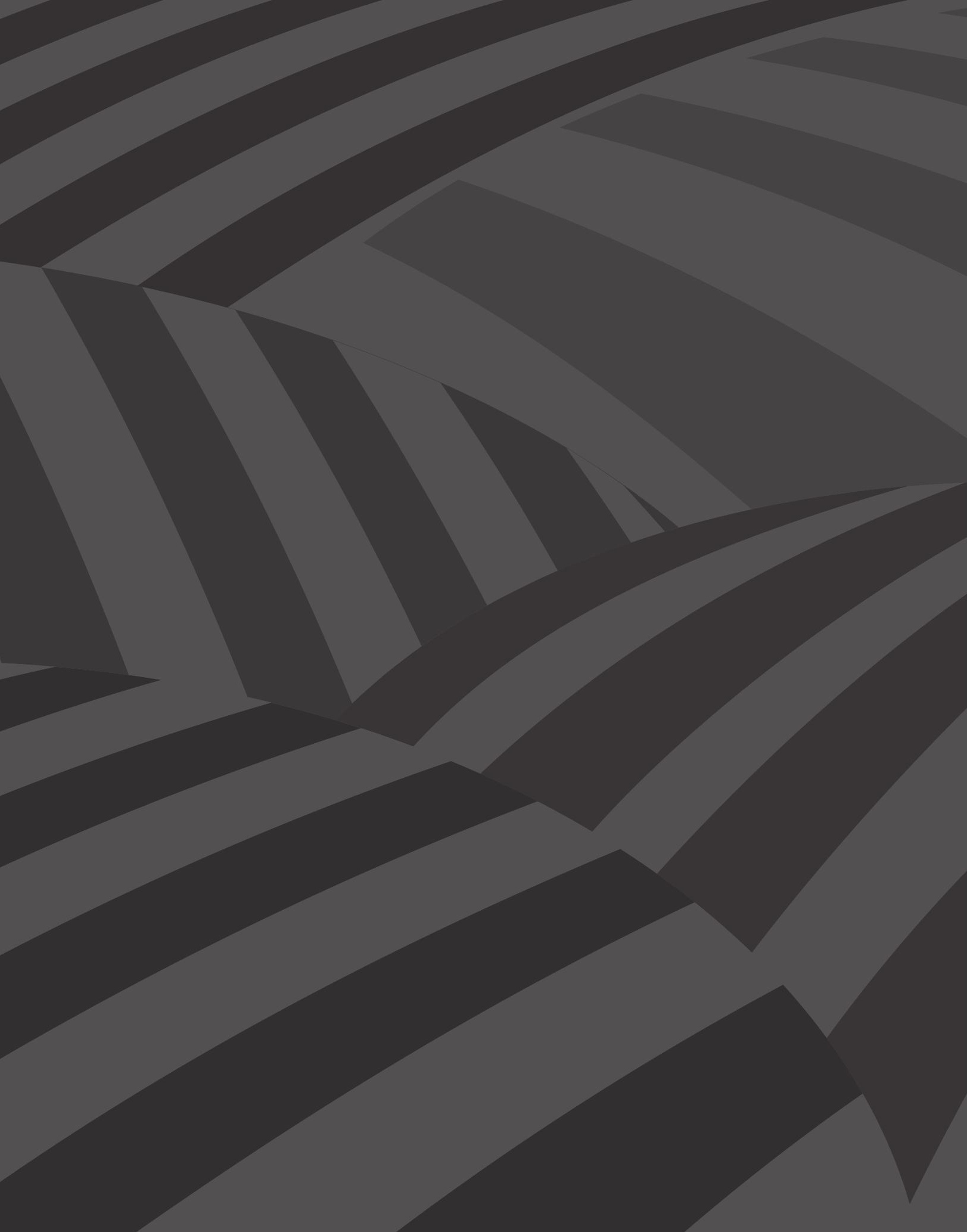




\title{
Desafíos en la educación rural- campesina: experiencias, posibilidades y transformaciones para la paz
}

\author{
Por Katerine Alejandra Duque Duque*
}

Resumen: el presente artículo busca brindar insumos para el debate sobre la educación rural como uno de los temas centrales para la implementación y consolidación de la paz en Colombia. Este documento se enfoca principalmente en las comunidades campesinas como actores fundamentales de la ruralidad, para lo cual se hace un diagnóstico de la educación rural a partir de las cifras institucionales de las entidades gubernamentales del sector y de las consideraciones de las organizaciones campesinas respecto a la situación actual de la educación en cada uno de sus territorios. Asimismo, expone el panorama de la educación rural, en razón a lo planteado en el acuerdo de paz firmado en noviembre del año 2016 entre el Gobierno Nacional y las FARC-EP y sugiere ocho líneas de acción para superar las problemáticas de la educación, con base en las propuestas adelantadas por las organizaciones campesinas del Suroccidente colombiano en el marco de la Estrategia de Fortalecimiento Organizativo para comunidades campesinas, adelantada por el Instituto de Estudios Interculturales en asocio con la Agencia Nacional de Tierras y la Agencia de Desarrollo Rural.

Finalmente, se establece que, para hablar de educación rural-campesina en el contexto de paz o educación para la paz, es necesario adelantar un estudio nacional con enfoque territorial sobre la situación de la educación. Para este propósito, se deben tener en cuenta los principios de interculturalidad, reconciliación y enfoque de género, y reconocer la importancia del arraigo de las escuelas en las comunidades y el papel de los docentes, del territorio y comprometidos con el desarrollo rural.

Palabras clave: educación, campesinos, interculturalidad, paz, reconciliación.

\section{Challenges to rural education: experiences, possibilities and transformations for peace}

Abstract: This article aims to provide inputs for discussion of rural education, as one of the central themes for the implementation and consolidation of peace in Colombia. This document has a central focus in the peasants communities as fundamental actors of rural life. The diagnosis of rural education

* Antropóloga e investigadora. Coordinadora de Espacios de Fortalecimiento Organizativo. Línea de Desarrollo Rural y Ordenamiento Territorial. Instituto de Estudios Interculturales. Pontificia Universidad Javeriana Cali 
are made based on the institutional figures of the governmental entities of the sector, as also on the consideration of peasant organizations about the current situation of the education in their territories. Additionally, it presents an overview of rural education with respect to the peace agreement signed in November of 2016 between the Colombian Government and FARC-EP.

Eight lines of action are suggested to overcome the problems of education, taking into account the proposals advanced by the peasant organizations of the Colombian Southwest in the framework of the Strategy of Organizational Strengthening for peasant communities, realized by the Instituto de Estudios Interculturales in associate with the Agencia Nacional de Tierras and the Agencia de Desarrollo Rural.

It's proposed that, to speak about rural education in the context of peace or education for the peace, it is necessary to advance a national study with territorial approach on the education situation. The principles of interculturality, reconciliation and gender focus must be taken into account, recognizing the importance of the roots of the schools to the communities, with teachers from the territory committed to rural development.

Keywords: education, peasants, interculturality, peace agreement, reconciliation.

Cómo citar este artículo: Duque, Katerine (2018). Desafíos en la educación rural-campesina: experiencias, posibilidades y transformaciones para la paz. Revista Controversia, 210, 135-176.

Fecha de recepción: 18 de enero del 2018

Fecha de aprobación: 25 de marzo del 2018

\section{Contexto}

causa de la ineficaz incidencia territorial de la institucionalidad
del sector público, los territorios rurales en Colombia han sido
histórica y sistemáticamente relegados de las acciones contundentes que podrían hacer efectivo el goce de sus derechos fundamentales. En consecuencia, el acceso inadecuado a los derechos consagrados en la Constitución Política del país - sociales, económicos, políticos, ambientales y culturales - ha imposibilitado un desarrollo apropiado, que permita condiciones sociales adecuadas en estos territorios.

El desarrollo implementado en los territorios rurales se enmarca en modelos económicos heredados de la colonia, la república y la modernidad. 
Pero, tal como lo conocemos, se consolida en el país en los años setenta con el modelo de industrialización y sustitución de importaciones, relacionado con el desarrollo del sector industrial, los procesos de urbanización, la modernización técnica y la intervención directa del Estado en la que el gobierno controla los mercados de productos locales y la exportación. En este marco, en Colombia se impulsaron proyectos de reforma agraria y aparatos fuertemente centralizados en el sector rural, que hacían énfasis en la producción de materias primas para la industria y para la generación de divisas (Pérez y Farah, 2002). Durante estos años, a pesar de los esfuerzos gubernamentales por fomentar el acceso a la tierra, los gremios y los grandes propietarios de tierras mantuvieron la concentración del poder social y político.

Ahora bien, en la década de los noventa, este modelo se transformó a partir de la Constitución Política de Colombia del año 1991 gracias a la apertura al neoliberalismo, mediante el cual, el progreso y desarrollo del país -y en particular del sector rural- se centraron en la competencia a partir del comercio internacional y de la modernización de las instituciones rurales. Con este modelo, se desmontaron los regímenes de protección sobre las exportaciones, se brindó un incentivo a la participación del sector privado, a la inversión de las trasnacionales y a la importación de productos agropecuarios. Resultado de esta implementación fue la desaceleración del crecimiento del valor de la producción agropecuaria, la reducción de áreas cultivadas, el monocultivo para la importación, la caída de la participación en el PIB del sector agropecuario, el incremento de la pobreza rural y la concentración de los ingresos rurales y de la propiedad de la tierra (Pérez y Farah, 2002)

En consecuencia, el modelo de desarrollo económico en el país, para el caso del sector rural, deja cifras alarmantes que evidencian que, pese al interés por sacar adelante el "progreso y desarrollo" en estos territorios, en la actualidad aún hay pobladores que permanecen al margen de unas acciones estatales y políticas efectivas, que permitan superar sus necesidades sociales y económicas en relación con el acceso a la tierra, 
a la vivienda y al sistema de salud o educación. Lo anterior deja en evidencia constantes históricas en estos territorios como el abandono del campo y la población rural; la exclusión de políticas públicas para ancianos, mujeres y niños; la violencia y el conflicto armado; y la concentración y el acaparamiento de la tierra. Frente a este último factor, los resultados del Censo Nacional Agropecuario muestran que, para el 2014, el 0,4 \% de la población tenía el $41 \%$ de la tierra y se presentaba el desplazamiento y despojo de 6,6 a 10 millones de hectáreas, así como desigualdad e inequidad, destrucción de la naturaleza y una discriminación y desigualdad que, para el índice de GINI, está en 0,85 (Páez, 2017).

Por lo tanto, la ineficaz implementación de un modelo de desarrollo económico y social adecuado para los pobladores rurales deja en evidencia varios aspectos que deben ser tenidos en cuenta a diferentes escalas y que explican, de alguna manera, el motivo por el cual una población, en su mayoría rural-campesina, optó hace más de sesenta años por tomar las armas para defender su territorio y transformar el statu quo.

El modelo de desarrollo, con sus implicaciones sociales, económicas y políticas se fue llenando de diversos matices, que dieron lugar a disputas entre apuestas antagónicas con una trayectoria histórica, es decir, entre las políticas que mantenían ese modelo y las políticas que lo cuestionaban y hasta apostaban por su transformación. Gracias a este antagonismo estructural, el progreso y avance en Colombia fueron de la mano de la guerra y la violencia, que adquiere trascendencia histórica en situaciones como la violencia entre partidos políticos (liberales y conservadores), la Guerra de los mil días, la época de la Violencia y el conflicto interno entre grupos al margen de la ley y el Estado.

La disputa representada por medio de los fusiles alcanzó momentos en los que, por iniciativa propia de los grupos armados o por interés del Gobierno de turno, se buscó una superación dialogada y negociada del conflicto armado, en razón a lo cual, es importante resaltar que en 
Colombia se han adelantado once procesos de paz ${ }^{1}$ con diferentes grupos armados ilegales. Estos procesos de diálogo y concertación han dejado una valiosa experiencia que debe ser tenida en cuenta de manera central: el conflicto de los territorios rurales se relaciona con el acceso a la tierra, tiene un enfoque más amplio que la mera obtención de un predio, a saber, se relaciona con el acceso integral a todos los derechos fundamentales (salud, vivienda, educación, trabajo, vida).

La consolidación del acuerdo de paz de esta última generación fue avalado en noviembre del año 2016 por el Gobierno Nacional y las FARC-EP; en este se destaca que la paz es calificada universalmente como un Derecho Humano Superior y es fundamental para el ejercicio de todos los demás derechos y deberes de todas las personas y ciudadanos (Acuerdo Final, 2016). A esto se debe que este articulado y su implementación estén abriendo la posibilidad de adelantar acciones adecuadas, legales y legítimas, en el ámbito institucional y comunitario, para superar la crisis profunda que tiene la ruralidad colombiana, mediante las cuales sea posible el reconocimiento de la diversidad de pobladores, de las necesidades básicas insatisfechas y los contextos regionales. Así mismo, la consolidación de los acuerdos de paz permite cuestionar ese modelo de desarrollo y reconocer las distintas apuestas que durante años han adelantado los actores rurales para hacer efectivo sus derechos.

En el marco de la negociación y la implementación de los acuerdos de paz, se reconoció a las comunidades campesinas como víctimas del conflicto armado que azotó al país en los territorios rurales; por tal motivo, en el articulado se consigna la necesidad de cerrar la frontera agrícola y velar por el acceso a los derechos de los campesinos,

(...) de manera que se logre en el menor plazo posible que los campesinos, las campesinas y las comunidades, incluidas las afrodescendientes e indí-

1 Los once se celebraron en los años: 1981, 1982, 1984, 1988, 1990, 1991, 1993, 1998, 1999,2002 y 2016. 
genas, ejerzan plenamente sus derechos y se alcance la convergencia entre la calidad de vida urbana y la calidad de vida rural, respetando el enfoque territorial, el enfoque de género y la diversidad étnica y cultural de las comunidades. (Acuerdo Final, 2016, p. 12)

Especialmente, se propende por una democratización del acceso a la tierra, en la que sus benefactores sean campesinos sin tierra o con tierra insuficiente, con el fin de fortalecer la economía campesina. En ese sentido, la implementación de estos acuerdos ha traído consigo debates fundamentales para la construcción de país, debates legislativos sobre la justicia transicional, participación política de los excombatientes y alcances de la reforma rural integral, entre otros. Igualmente, ha estado acompañada de elementos importantes como la reorganización de las fuerzas armadas ilegales guerrilleras y paramilitares, las movilizaciones sociales en las que se exigen hechos reales y los asesinatos de los líderes sociales, proceso que, de acuerdo a la información de la Defensoría del Pueblo, para el 5 de julio de 2018, sumaba ya 311 personas (Cárdenas, 2018).

En medio de este contexto, la educación se convierte en un tema central para la construcción de paz, ya que permite comprender los mecanismos adecuados para cultivar nuevos conocimientos para la paz y posibilita el empoderamiento de los ciudadanos como artífices y gestores de su construcción. A pesar de que el papel de la educación en las sociedades modernas ha sido fuente de estudio y análisis en la academia colombiana y del mundo, el hecho de recalcar este debate suscita la afirmación de que no está acabado y que requiere esfuerzos cruciales para comprender su papel en todos los niveles y ámbitos posibles, dado que sobrepasa el análisis académico/investigativo y se cimienta en la sociedad, en general, y en los individuos, en particular.

Ya es hora de entender que este desastre cultural no se remedia ni con plomo ni con plata, sino con una educación para la paz, construida con amor sobre los escombros de un país enardecido donde nos levantamos temprano para seguirnos matándonos los unos a los otros. Una educación 
inconforme y reflexiva que nos incite a descubrir quiénes somos en una sociedad que se parezca más a la que merecemos. Que nos oriente desde la cuna en la identificación temprana de las vocaciones y las aptitudes congénitas para poder hacer toda la vida solo lo que nos guste, que es la receta mágica de la felicidad y la longevidad. En síntesis, una legítima revolución de paz que canalice hacia la vida la inmensa energía creadora que durante casi dos siglos hemos usado para destruirnos y que reivindique y enaltezca el predominio de la imaginación. (García Márquez, 1998; Díaz, 2017).

Como lo evidencia Gabriel García Márquez en la cita anterior, la construcción de paz no es ajena a las dinámicas educativas y formativas, por lo tanto, las comunidades educativas, en todos los niveles, estudiantes, educadores, padres de familia, trabajadores y comunidades, están llamadas a consolidar opciones de paz, a acabar con la violencia y a gestionar los conflictos. Con esta antesala, es necesario analizar el estado de la educación en los contextos rurales, es decir, determinar cómo está la pertinencia, calidad y cobertura, entre otros aspectos, en los espacios que irreparablemente han sido más golpeados por la violencia armada y estructural.

El rol de la educación es fundamental para la democracia del país, pues permitiría construir y consolidar las condiciones necesarias para una paz sostenible, por lo tanto, es fundamental establecer cómo hacer real la garantía del derecho a una educación de calidad en relación con la dignidad humana, la pertinencia desde la diversidad, el enfoque de género y la inclusión (Red de Educación para la paz y los Derechos Humanos, 2015).

Este artículo busca dar insumos sobre la educación rural para la paz con enfoque intercultural, con base en el trabajo realizado con organizaciones campesinas. En consecuencia, se espera poder hacer evidentes los avances, retrocesos y retos para la implementación de los acuerdos de paz, mediante su desarrollo a partir de cuatro puntos: 1) diagnóstico de la educación rural, 2) educación en el marco de los acuerdos de paz, 3) 
experiencia de los Espacios de Fortalecimiento Organizativo y 4) Retos y propuestas que tiene la educación rural para la paz. Es importante destacar que el diagnóstico correspondiente a la educación rural se hará en doble vía. En la primera, se considera la situación nacional de la educación respecto a las cifras institucionales de diferentes entidades de corte nacional. En la segunda, se tiene en cuenta un diagnóstico participativo en el marco de la Estrategia de Fortalecimiento Organizativo con organizaciones campesinas que tienen incidencia en los departamentos de Nariño, Cauca, Valle del Cauca, Huila, Caquetá y Putumayo.

Además, es fundamental considerar a la interculturalidad como proyecto político y eje transversal del planteamiento, pues esta posibilita el diálogo entre culturas, la construcción de sociedades diferentes y la formación de "ciudadanos conscientes de las diferencias y capaces de trabajar conjuntamente en el desarrollo del país y en la construcción de una sociedad justa, equitativa, igualitaria y plural” (Walsh, 2010, p. 2).

\section{Diagnóstico de la educación rural}

El análisis de este apartado se desarrolla con base en los aspectos cualitativos y cuantitativos de datos sobre la educación rural, en especial, se centra en los datos obtenidos en la categoría rural disperso, a la que se alude en relación con la situación del sujeto campesino. Con este fin, se estudian algunos datos y resultados de las instituciones gubernamentales sobre el tema, así como los aspectos evidenciados por organizaciones campesinas del suroccidente colombiano, que fueron participantes de la Estrategia de Fortalecimiento Organizativo. Estos datos nos permiten brindar un análisis general de la situación de la educación rural; se espera que, tras estudiarlos a la luz de varios aspectos importantes en el marco de la implementación de los acuerdos de paz, estos se puedan transformar en posibilidades.

De acuerdo a los datos suministrados por la Misión Transformación del Campo (2014), existe un porcentaje de analfabetismo de la zona rural 
dispersa ${ }^{2}$ del $12,5 \%$, la tasa de permanencia en el sistema educativo es del $48 \%$, la matricula en la educación secundaria no supera el 68 \% y el porcentaje de personas que han terminado el bachillerato en las zonas rurales es, en hombres, del $32 \%$, y en mujeres, del $36 \%$.

De acuerdo con el Censo Agropecuario (2014), se obtuvieron los siguientes resultados para el área rural dispersa: el $23 \%$ de los hogares censados presentan analfabetismo y el $82,4 \%$ bajo logro educativo. El $10,2 \%$ de los hogares registran inasistencia escolar, $22,4 \%$ rezago escolar y $4,9 \%$ falta de acceso a servicios de primera infancia. Por otro lado, el 17,1 \% de los niños menores de cinco años asiste a una institución; el $20,3 \%$, entre los cinco y dieciséis años, no asiste a centros educativos; y el $73,7 \%$ de la población entre diecisiete y veinticuatro años no tiene acceso a la educación, frente un 26,3 \% que sí lo tiene.

El censo también demuestra que el $51,1 \%$ de las personas de veinticuatro años o más cuentan con un nivel educativo de básica primaria, el $18,3 \%$ afirman no tener ningún nivel educativo, seguidos del 12,4 \% que afirman cumplir con básica secundaria y el 10,0\% restante con educación media. La Gran Encuesta Integral de Hogares (GEIH) practicada en el año 2015 expone que, tan solo el 21 \% de los jóvenes que hacen parte de los territorios rurales logran terminar la educación media y el $6 \%$ puede continuar con su educación después de la secundaria. De ellos, el $50 \%$ no consigue obtener un título, $44 \%$ alcanza un título técnico o tecnológico y solo el $6 \%$ logra el título universitario.

Es importante subrayar que, para el año 2015, esta misma encuesta muestra el aumento exponencial de la brecha existente entre lo urbano y lo rural: en el año 2005, 1,2; en el año 2015, 1,6. En consecuencia, en cobertura neta de educación secundaria y media la brecha se constituye en más de 20 puntos porcentuales; además, cerca del $50 \%$ de

2 Rural disperso es el área que se caracteriza por la disposición dispersa de viviendas y explotaciones agropecuarias. No cuenta con un trazado o nomenclatura de calles, carreteras, avenidas y demás (DANE, 2005). 
los establecimientos educativos tienen un desempeño inferior y bajo, frente al $20 \%$ de los establecimientos urbanos (Dirección Nacional de Planeación, 2014).

De acuerdo a los datos obtenidos por el Ministerio de Educación Nacional, para el año 2014, de 7168 sedes rurales en el país, el $80 \%$ no cuenta con red de gas, el $70 \%$ no tiene alcantarillado, el $40 \%$ está sin acueducto, el $13 \%$ sin energía eléctrica y el $27 \%$ de los colegios se inundan. La oferta formativa próxima a las viviendas cubre tan solo el acceso a los niveles de básica primaria y, en menor medida, a los de secundaria, lo que imposibilita la continuidad del proceso (Ministerio de Educación Nacional, 2017). A lo anterior, se suma la clausura de 2713 escuelas rurales en los años 2006 al 2017, debido al incumplimiento en la cantidad de estudiantes requeridos para su funcionamiento, según los datos de la dirección de fomento del Ministerio de Educación Superior (Semana, 2017).

En cuanto a los docentes, para el año 2015 tenían presencia en los territorios urbanos con un porcentaje de 65,60 \% frente a los rurales con 33,20\% . Hay un alto porcentaje de docentes que no tienen la formación adecuada ya que su último nivel educativo aprobado es el bachillerato, con un $80 \%$, y el 65 \% carece de título (Dirección Nacional de Planeación, 2014).

Otro de los aspectos a tener en cuenta es que los docentes de los territorios rurales han sido y siguen siendo víctimas de amenazas. Por ejemplo, de enero del 2015 a marzo de 2016, se registraron 605 profesores de colegios víctimas de amenazas (Semana, 2016); para el año 2017, tan solo en Antioquia fueron amenazados 154 profesores (Moreno, 2017).

En la actualidad, uno de los problemas que enfrenta la educación rural gira en torno al Programa para la Alimentación Escolar (PAE), cuyo cubrimiento, a pesar de estar proyectado en un $100 \%$ en el campo, solo cobija a los estudiantes matriculados en las instituciones que tienen 
jornada única (Semana, 2017). Aunado a lo anterior, el programa presenta problemas de corrupción; para noviembre del año 2017, la fiscalía detectó que trece departamentos presentaban prácticas ilegales en el manejo presupuestal en los contratos, que se vieron reflejadas en un manejo inadecuado de cerca de 140 mil millones de pesos (Semana, 2017).

La implementación de la jornada única, mediante el Decreto 1075 del año 2015, se llevó a cabo bajo el supuesto de que, si los estudiantes tenían más tiempo en las instituciones educativas, se podría mejorar la calidad de las mismas, ya que esto permitiría el fortalecimiento de sus capacidades y competencias (Plan Nacional de Desarrollo 2014-2018). No obstante, esta política trajo consigo debates centrales en el sector educativo, pues el principal resultado de este proceso es el recorte de una hora presencial de los estudiantes en las instituciones educativas, el desconocimiento de la participación activa de los docentes y la disminución de la inversión en las instituciones públicas, que se han visto seriamente afectadas en su calidad (Atencio, 2018).

Otro problema que se presenta en el contexto rural es la pertinencia de la educación, pues en muchos casos se implementan contenidos, metodologías y pedagogías propias de los territorios urbanos. Esto deriva en la baja calidad educativa de los estudiantes, que lamentablemente son evaluados bajo los mismos parámetros en las Pruebas de Estado, lo que causa segregación e inequidad a la hora de acceder al campo educativo y laboral. Estos sucesos desconocen las lógicas propias de la construcción de conocimiento a nivel rural: dinámicas económicas, políticas, culturales y sociales, que han marcado históricamente a estas comunidades y han trazado la necesidad de adelantar otras estrategias formativas y educativas ajenas al aula escolar y a la educación formal. 


\section{Gráfico 10. Distribución de los establecimientos educativos según zona y categorias de desempeño en las pruebas SABER 11, 2013.}

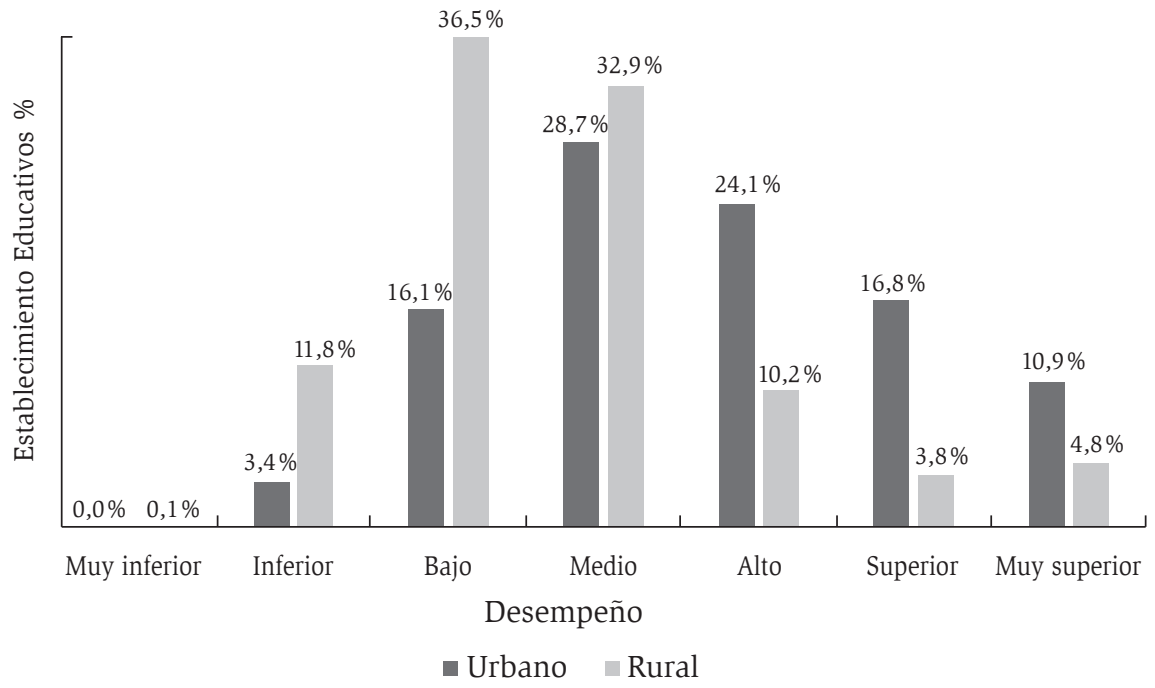

Fuente: Instituto Colombiano para el Fomento de la Educación Superior (Icfes).

De acuerdo a los resultados de las calificaciones obtenidas en las pruebas Icfes, hay un mayor porcentaje de jóvenes provenientes de los territorios rurales que obtienen la calificación muy inferior, inferior, bajo y medio, frente a los jóvenes de los territorios urbanos, que en su mayoría obtienen calificación alto, superior y muy superior.

Como ya se ha dicho, la educación rural convoca la participación de tres actores sociales principales: indígenas, afrocolombianos y campesinos, sin desconocer que en el mundo rural se encuentran diversos actores económicos, institucionales y comunitarios. En el marco de la Constitución Política de 1991 y del reconocimiento de la diversidad étnica desde la clave multicultural colombiana, tanto el indígena como el afrocolombiano fueron incluidos como sujetos especiales de derechos. En contraparte, el campesinado fue reconocido únicamente como 
trabajador agrario, con lo cual se desconocen las múltiples territorialidades que lo caracterizan como grupo social heterogéneo con identidad y prácticas propias.

De lo anterior se colige que, esta exclusión “exacerba las tensiones por la competencia de espacios de representación y de acceso a derechos diferenciados entre poblaciones organizadas en torno a intereses por el acceso a la tierra, o alrededor de elementos étnico-culturales” (Duarte, 2017). En consecuencia, es posible identificar situaciones de orden comunitario, en las que se presentan tensiones o conflictos por el acceso a la educación. Por ejemplo, para el caso del departamento del Cauca, en relación con el tema de la educación se han presentado enfrentamientos entre comunidades indígenas y campesinas e indígenas y afrocolombianas, suscitados por la educación propia, reconocida en el marco de los derechos étnicos diferenciales a las comunidades indígenas.

En San Andrés de Pisimbalá hay un colegio por el que hace cinco años se inició la disputa. Los campesinos argumentan que los indígenas se lo han tomado para imponer su ley; los indígenas sostienen que los campesinos no quieren reconocer su derecho a una educación propia. (Benito, 2015)

A partir de lo anterior, es necesario ubicarse en los departamentos de Putumayo, Caquetá, Huila, Nariño, Cauca y Valle del Cauca, en donde hacen presencia las organizaciones campesinas, la Asociación Nacional de Usuarios Campesinos (ANUC), el Comité de Integración del Macizo Colombiano (CIMA), el Coordinador Nacional Agrario (CNA), el Proceso de Unidad Popular del Suroccidente Colombiano (PUPSOc) y la Federación Nacional Sindical Unitaria Agropecuaria (Fensuagro), participantes de la Estrategia de Fortalecimiento Organizativo del año 2016, adelantadas por el Instituto de Estudios Interculturales de la Pontificia Universidad Javeriana Cali, en asocio con la Agencia Nacional de Tierras y la Agencia de Desarrollo Rural. 
En el marco de la discusión sobre la educación rural, las organizaciones campesinas han evidenciado los siguientes aspectos:

- Es una educación coercitiva, que niega otros conocimientos y aprendizajes.

- Presenta un frecuente abandono del proceso formativo, debido a la economía fácil que representan el narcotráfico y el microtráfico.

- Hace falta una verdadera vocación docente.

- Carece de una formación en torno al cuidado del medio ambiente.

- Determinan un solo docente para todos los alumnos de la escuela.

- Los padres de familia presentan falta de compromiso de con el proceso formativo.

- No hay apoyo de las universidades para que sea posible la vinculación de los jóvenes a los programas de educación superior.

- La herramienta educativa del internet no es suficiente, ya que no hay acceso a la red en todos los territorios rurales.

- No se pregunta por lo que quieren los jóvenes rurales.

- Existe una gran dependencia de las instituciones educativas como el SENA, que no permite empoderar a las comunidades rurales.

- Falta un proceso de contextualización y conocimiento de las necesidades de la población rural, frente a lo cual, la educación no propone transformaciones. 
- No tiene en cuenta las dinámicas propias o procesos autónomos de construcción de conocimiento de las comunidades campesinas en relación con las escuelas campesinas, las huertas caseras, escuelas ambientales y del agua y la economía propia.

- No propone un vínculo fuerte y real entre la familia, la escuela y la comunidad.

- No hay acceso a la educación superior por la falta de recursos para el pin de admisión, el nivel de conocimiento de la prueba de admisión, el acompañamiento en el proceso formativo y el apoyo financiero para evitar la deserción.

- Genera tensiones territoriales o conflictos territoriales, que se deben al diferenciado acceso al proceso formativo.

- No se incentiva el conocimiento alrededor de los aspectos agrícolas y agropecuarios.

- Se presentan experiencias con docentes, en el marco de la institucionalidad y el trabajo extramural, que tienen impedimento de tipo legal para avanzar en su práctica pedagógica.

- Se evidencia la pérdida de identidad y valores campesinos, pues estos no son promovidos desde las instituciones educativas.

- El sistema de educación es tradicionalista y autoritario.

Con base en lo anterior, se pueden rastrear los siguientes elementos que hacen parte del diagnóstico institucional y comunitario: nivel de analfabetismo, inasistencia escolar, bajo nivel educativo, precaria situación de infraestructura, falta de docentes, brecha urbano-rural, violencia en los territorios, problemas con el programa para la alimentación escolar, pertinencia, ignorancia frente al cuidado del medio ambiente, ausencia 
del reconocimiento de los saberes propios que tienen las comunidades campesinas y conflictos territoriales interétnicos e interculturales.

Ahora bien, es importante destacar que, el Ministerio de Educación Nacional ha adelantado estrategias que permitan superar la inequidad en el acceso al sistema educativo para los pobladores rurales, pero estas, lamentablemente, no han sido del todo efectivas. Dentro de las estrategias que ha impulsado el Ministerio de Educación en Colombia para los sectores rurales, se pueden destacar: el cambio de modelo hacia modelos educativos más flexibles; la implementación de la Escuela Nueva como mecanismo para el acceso a la educación, en la cual cada curso cuenta con uno o más maestros; la promoción de una participación activa de los niños y los maestros, entendidos como facilitadores del aprendizaje.

Para el caso de la Básica Secundaria, de sexto a noveno, se ha implementado el programa de Postsecundaria con jóvenes de doce a diecisiete años, el cual cuenta con 42 módulos a fin de flexibilizar y diversificar el currículo escolar en las zonas rurales; la Telesecundaria como estrategia educativa que se apoya en el material impreso y en la televisión como herramienta didáctica para el aprendizaje; y el Sistema de Aprendizaje Tutorial (SAT), que tiene un enlace directo entre las necesidades socioeconómicas de la comunidad rural y el currículo de aprendizaje, a través de proyectos productivos: el impulsor ( 6 y 7 grado), el práctico (8 y 9 grado) y el bachiller (10 y 11 grado) en desarrollo rural. Dentro de los programas para el sector educativo del Plan Nacional de Desarrollo 2014-2018, se destaca la implementación de la Jornada Única Escolar, con el fin de extender la permanencia de los niños en el colegio; la creación de un Fondo de Financiamiento de la Infraestructura Educativa; el programa de Educación Inicial para los niños menores de cinco años y el programa de Educación Media para todos (Ministerio de Educación Nacional, 2015) 


\section{La educación en el marco de los acuerdos de paz}

El articulado final del acuerdo firmado entre el Gobierno Nacional y las FARC-EP en noviembre del año 2016 plantea la necesidad de implementar estrategias efectivas para una acción eficaz del Estado en todo el territorio nacional, en el marco del reconocimiento de los impactos de la violencia armada y social en los territorios rurales del país y la vulneración de los derechos fundamentales a sus pobladores.

En ese sentido, el propósito del primer punto de los acuerdos de paz sobre la "Reforma Rural Integral” es:

Contribuir a la transformación estructural del campo, cerrando las brechas entre el campo y la ciudad y creando condiciones de bienestar y buen vivir para la población rural. Para esto debe integrar las regiones, contribuir a erradicar la pobreza, promover la igualdad y asegurar el pleno disfrute de los derechos de ciudadanía.

Se reconoce que uno de los elementos susceptibles a mejorar y transformar es la educación impartida en los territorios rurales, específicamente para los pobladores rurales y las personas que continúan en la reincorporación a la vida civil.

Entre tanto, se expone la necesidad de subsanar el problema de acceso a la tierra para una transformación oportuna e integral del campo, para lo cual es indispensable establecer planes nacionales financiados por el Estado, destinados a ofrecer garantía de bienes y servicios como el de la educación. En razón a esto, como objetivos para la educación rural se destacan:

- La cobertura universal con atención a la primera infancia.

- Los modelos flexibles de educación preescolar, básica y media, que se adapten a las necesidades de las comunidades y del medio rural, con un enfoque diferencial.

- La construcción, reconstrucción, mejoramiento y adecuación de la infraestructura educativa rural, incluida la disponibilidad y 
permanencia de personal docente calificado y el acceso a las tecnologías de la información.

- La garantía de la gratuidad educativa para la educación preescolar, básica y media.

- La oferta de programas e infraestructura de recreación, cultura y deporte.

- El mejoramiento de las condiciones para el acceso y la permanencia en el sistema educativo de los niños, niñas y adolescentes a través de un acceso gratuito a útiles, textos, alimentación escolar y transporte.

- La incorporación de la formación técnica agropecuaria en la educación media.

- La disponibilidad de becas con créditos condonables, que garanticen el acceso de los hombres y mujeres rurales más pobres a servicios de capacitación técnica, tecnológica y universitaria; cuando sea pertinente, estos deben incluir apoyos a la manutención.

- La promoción de la formación profesional de las mujeres en disciplinas no tradicionales para ellas.

- La implementación de un programa especial para la eliminación del analfabetismo rural.

- La promoción de la ampliación de oferta y la capacitación técnica, tecnológica y universitaria en áreas relacionadas con el desarrollo rural.

El numeral 1.3.2.2 del acuerdo expone el tema de la educación rural y plantea la importancia de:

Brindar atención a la primera infancia, garantizar la cobertura, la calidad y la pertinencia de la educación y erradicar el analfabetismo en las áreas rurales, así como promover la permanencia productiva de las y los jóvenes del campo, y acercar las instituciones académicas regionales a la construcción 
del desarrollo rural, el Gobierno Nacional creará e implementará el Plan Especial de Educación Rural.

De esta manera, se exhortó al Ministerio de Educación Nacional a desarrollar los lineamientos que debería tener la educación en los contextos rurales, para lo cual, el ministerio viene adelantando el Plan Especial de Educación Rural (PEER) ${ }^{3}$, proyectado a diez años y dirigido a todas las zonas rurales, especialmente, a los 170 municipios focalizados por la Oficina del Alto Comisionado para la Paz. Dichos municipios serán directamente el foco de trabajo de la Agencia de Renovación del Territorio (ART) ${ }^{4}$ en la implementación de los acuerdos de paz, bajo el marco del Programa de Desarrollo Rural (PDET) ${ }^{5}$, en cuyos pilares se encuentra el PEER.

A nivel territorial (ver figura 2), se puede indagar por la presencia de los PDET y la implementación del PEER, a través de los cuales se pueden reconocer los municipios y departamentos que cumplen con los criterios de priorización: niveles de pobreza, en particular, de pobreza extrema y las necesidades insatisfechas; grado de afectación derivado del conflicto; debilidad de la institucionalidad administrativa y de la capacidad de gestión; y presencia de cultivos de uso ilícito y de otras economías ilegales. En consecuencia, las apuestas en el PEER deben estar enfocadas

3 Este programa no tiene un documento formal, pero se conoce el borrador, del cual se hizo el análisis correspondiente.

4 La Agencia de Desarrollo Rural fue creada mediante el Decreto 2366 de 2015, con el objetivo de "coordinar la intervención de entidades nacionales y territoriales en zonas rurales afectadas por el conflicto, priorizadas por el Gobierno nacional, a través de la ejecución de planes y proyectos para la renovación territorial de estas zonas, que permitan su reactivación económica, social y su fortalecimiento institucional para que se integren de manera sostenible el desarrollo del país" (Presidencia de la República. Colombia. Agencia de Renovación del Territorio).

5 Es un programa subregional de transformación integral del ámbito rural a diez años, a través del cual se ponen en marcha con mayor celeridad los instrumentos de la Reforma Rural Integral en los territorios más afectados por el conflicto armado, la pobreza, las economías ilícitas y la debilidad institucional. Además, es un instrumento de planificación y gestión para implementar de manera prioritaria los componentes de la Reforma Rural Integral y las medidas pertinentes que establece el acuerdo final, en los municipios priorizados. 
hacia las propuestas comunitarias y una lectura territorial de los municipios y la capacidad institucional, sobres las cuales es fundamental plantearse las siguientes preguntas: ¿Educación y territorio? ¿Educación para el desarrollo rural con enfoque territorial?

Figura 1. Mapa Regiones PDETS.

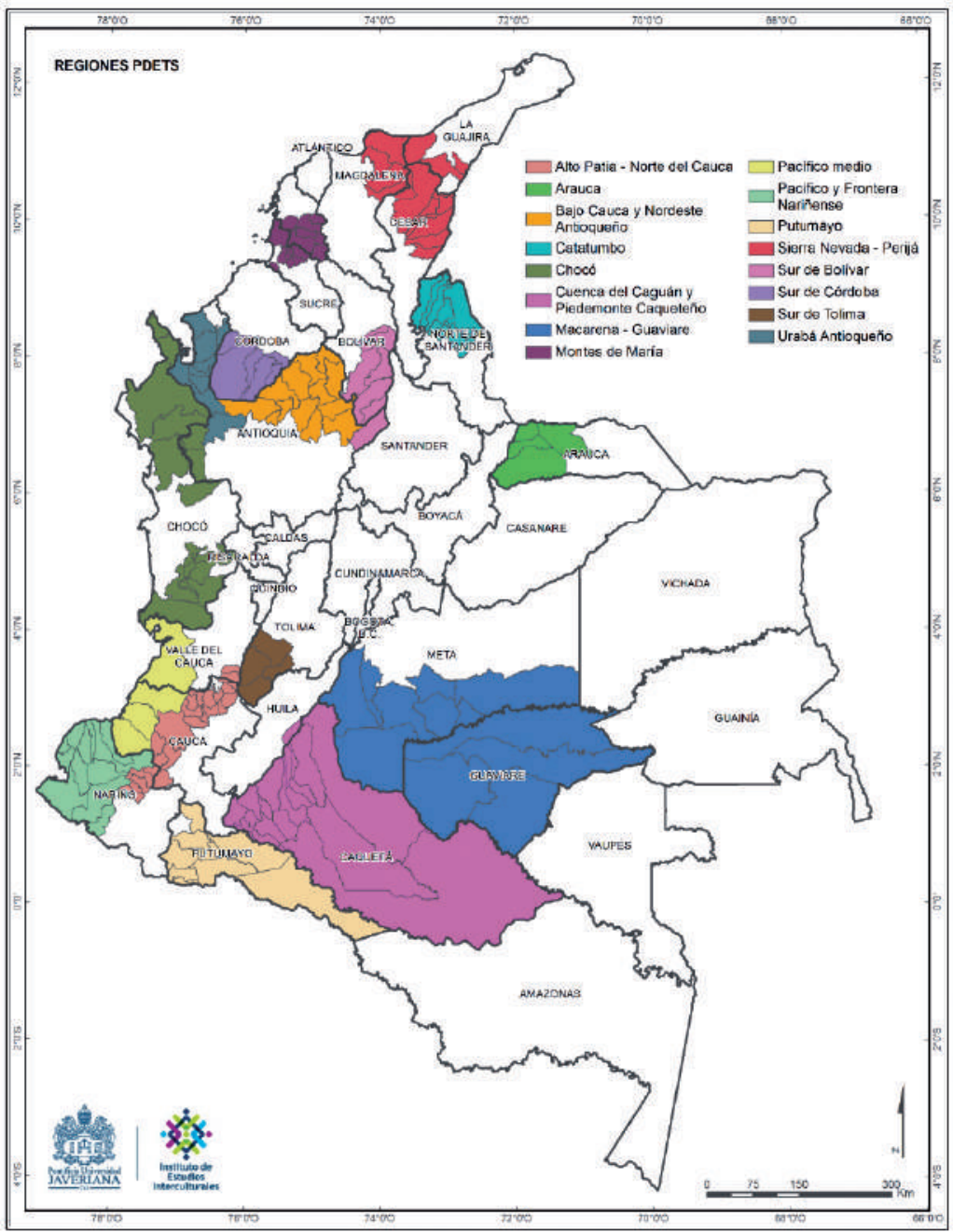

Fuente: elaboración propia, Instituto de Estudios Interculturales (2018). 
Es fundamental comprender que, el enfoque territorial, tal como lo plantea el acuerdo final, posibilita la reducción de desequilibrios y la superación de las inequidades territoriales; además, deja en evidencia la prioridad de articular políticas públicas en diferentes niveles, que incluyan la participación de la sociedad civil, en este caso, pobladores de los territorios rurales, a fin de que la situación de los territorios sea transformada en términos productivos, sociales e institucionales. Así, la educación con enfoque territorial permitirá que las comunidades sean agentes centrales para el desarrollo rural, que las comunidades se empoderen y que los contenidos de la educación formal acojan los esfuerzos comunitarios e institucionales para el desarrollo de estos territorios de "manera equitativa y sostenible, tanto desde el punto de vista social como del medio ambiente, gracias un mejor acceso a bienes (naturales, físicos, humanos, tecnológicos y el capital social) y servicios, y al control del capital productivo" (Unesco, 2004, p. 18).

Es importante destacar la inversión que ha realizado la ART en el marco de la implementación de los PDET en Pequeñas Infraestructura Comunitarias $^{6}$, entre las que se encuentran la dotación de escuelas, canchas multideportivas, parques, casetas comunitarias, puentes peatonales y servicios de luz con paneles solares. Para enero de 2018, en 52 municipios priorizados hubo 1283 obras entregadas y en proceso de ejecución, equivalentes a \$134 mil millones de pesos, de las cuales 256 se establecen en la subregión Alto Patía del norte del Cauca (El Nuevo Liberal, 2018).

El Plan Especial de Educación Rural es un documento borrador dinamizado por el Ministerio de Educación Nacional, que, a la fecha, lamentablemente, no cuenta con el documento final y con el presupuesto necesario para que sea efectiva su implementación. Aunque para su priorización se establecen los mismos municipios de los PDET, no hay

6 Es una estrategia de la Agencia de Renovación Territorial para atender las principales necesidades de las comunidades rurales en corto tiempo, mejorar su calidad de vida y fortalecer las capacidades institucionales (Presidencia de la República. Colombia. Agencia de Renovación del Territorio). 
una estrategia sectorial para la articulación institucional que posibilite la instauración de lo consignado en el punto 1 de los acuerdos de paz por ambas carteras, lo que, indudablemente, pone en desventaja la colocación del plan y, de forma integral, los cambios necesarios en torno a la educación rural, planteados en las asambleas adelantadas en los PDET.

El PEER (2017) propone como objetivo enfrentar los:

retos de la educación rural que contribuyan a la eliminación de las brechas existentes y promuevan una educación de calidad para todos los niños, adolescentes jóvenes y adultos del país, al igual que respondan de manera oportuna y pertinente a sus características individuales, la región, cultura y contexto en el que se desarrollan. (p. 1)

A su vez, reconoce que la educación es:

uno de los mecanismos que más puede incidir en la reducción de estas brechas, al afectar de manera directa las capacidades y habilidades de los ciudadanos, así como la dinamización de la economía local, el fomento de las vocaciones del territorio, la potencialización de los procesos de cohesión y la participación ciudadana. (p. 69)

En el plan se afirma que, en el marco del posconflicto, la educación debe estar orientada hacia tres principios: 1) proceso de sanación de heridas entre victimarios y víctimas; 2) proceso de formación de ciudadanos, orientado al respeto de la diferencia y a la resolución de conflictos de forma pacífica; y 3) oportunidad política para responder a deudas históricas del Estado y cerrar brechas socioeconómicas y políticas (p. 2).

Es importante destacar la instalación de la Mesa Nacional de Educación Rural en el año 2017, con la participación de 72 organizaciones e instituciones dedicadas a la educación, cuyo objetivo es definir una agenda de trabajo con el Ministerio de Educación Nacional, para dar continuidad al desarrollo de acciones que fortalezcan el Plan de Educación Rural: 
Estas organizaciones, instituciones, maestros y líderes de base coinciden en afirmar que parte de la enorme brecha de inequidad y la desigualdad en oportunidades y garantías que viven las poblaciones rurales del país son causa del sistema educativo que no está diseñado con enfoque diferenciado para las personas que viven y trabajan en el campo. (Cinep, 2017)

Además, se destacan dos decretos vía fast track, relacionados con la educación rural. Dentro de sus considerandos, el Decreto 882 de 2017 se plantea el derecho a la educación, la lucha contra el analfabetismo y la necesidad de fortalecer la planta docente, el cual estará enmarcado en el PEER y se fijará los siguientes objetivos: 1) promover un concurso de méritos docentes en el que pueden participar bachilleres; 2) establecer una planta de cargos docentes con una destinación exclusiva a zonas afectadas por el conflicto; 3 ) inscribir la carrera docente tras el periodo de prueba. Para el caso del Decreto 892 de 2017, pretende extender el periodo para que 55 instituciones de educación superior ubicadas en zonas del PDET acrediten sus programas de licenciatura.

Es clave reconocer que, a pesar de que el articulado insta al Ministerio de Educación a adelantar el PEER, este programa ha tenido problemas en su ejecución a causa de la falta de presupuesto y la coyuntura política del país, relacionada con el cambio del Gobierno nacional.

\section{Propuestas de educación rural para la paz}

Para adelantar un panorama del diagnóstico de la educación rural en el país, es fundamental revelar algunas rutas que podrían ser fundamentales para superar las problemáticas encontradas y, además, tengan en cuenta lo postulado en los acuerdos de paz. Así mismo, al analizar los postulados de educación que se han planteado para los territorios rurales en el marco de los acuerdos de paz, se deben reconocer otros aspectos que sin duda alguna sobrepasan los lineamientos esbozados en el documento final de acuerdos y su normatividad. 
Estas rutas deben conducir a la consideración de la educación como un derecho fundamental y bien común, ya que, no solo debe fortalecer el principio de la democracia en el país, sino que debe ser una herramienta para gestionar, transformar y superar el conflicto armado presente en los territorios rurales. Sin lugar a dudas, urge que dicha herramienta sea utilizada de manera creativa y diferente a lo que por años se ha realizado.

Bajo la premisa de que la educación debe permitir sembrar identidad y cosechar paz, se evidencian en esta sección tres aspectos fundamentales: el primero es el resultado de una sistematización practicada en el marco de la Estrategia de Fortalecimiento Organizativo del año 2017, en la que es posible rastrear las propuestas de las comunidades campesinas frente a las problemáticas encontradas en la educación que reciben. Un segundo aspecto expone los resultados de la construcción de política pública en educación campesina en el marco del reconocimiento del campesinado como sujeto político y de derechos, realizado por la Mesa Campesina del Cauca CIMA-CNA/PuPSOc-Fensuagro. Finalmente, se evidencian las líneas estratégicas adoptadas para adelantar una agenda de trabajo, con el objetivo de superar las problemáticas reconocidas de cara a la educación rural-campesina.

En el marco de los Espacios de Fortalecimiento Organizativo con las organizaciones campesinas, se pudieron rastrear propuestas, discriminadas por departamentos, que surgen del sentir del campesinado en aras de superar el problema de la educación rural: 


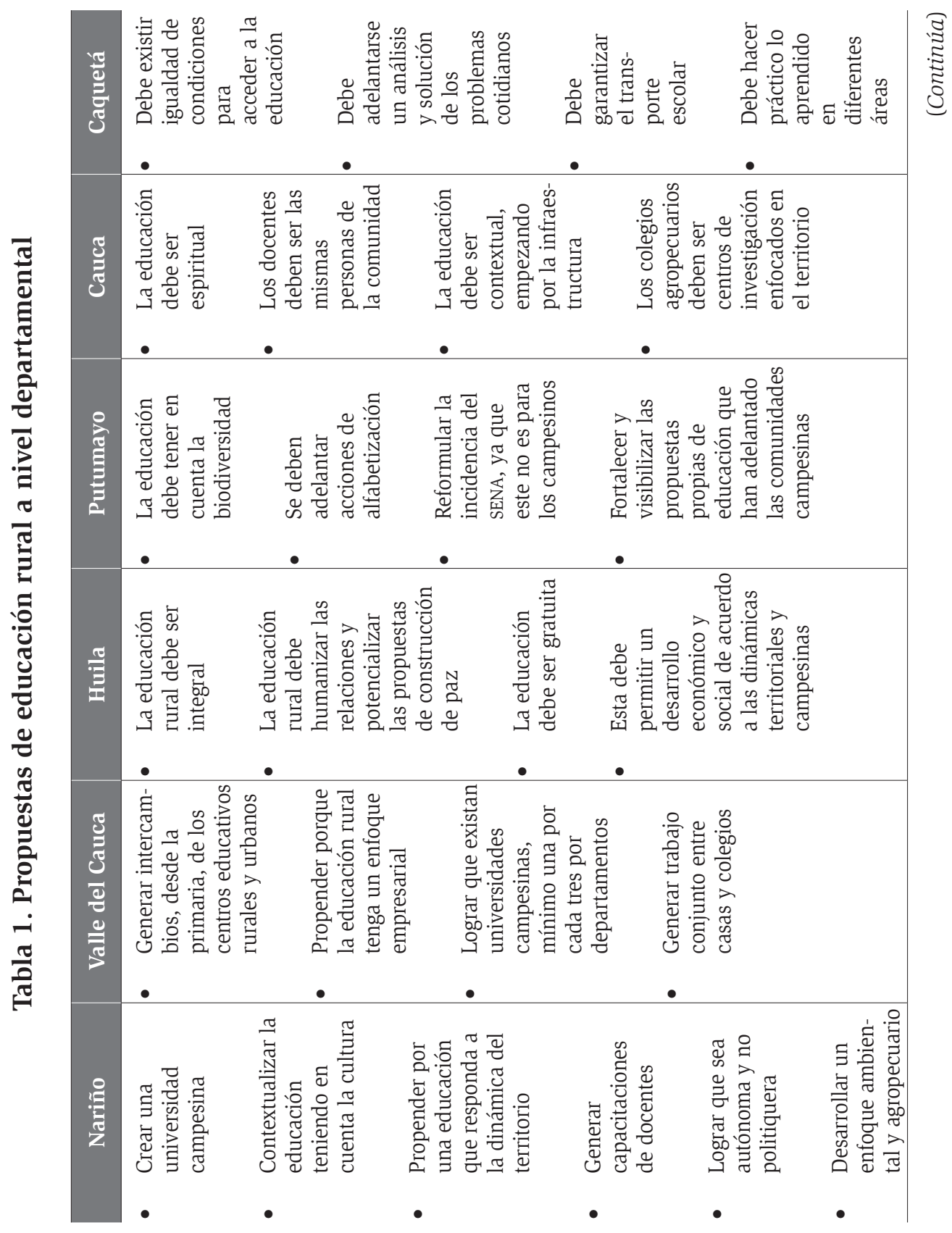




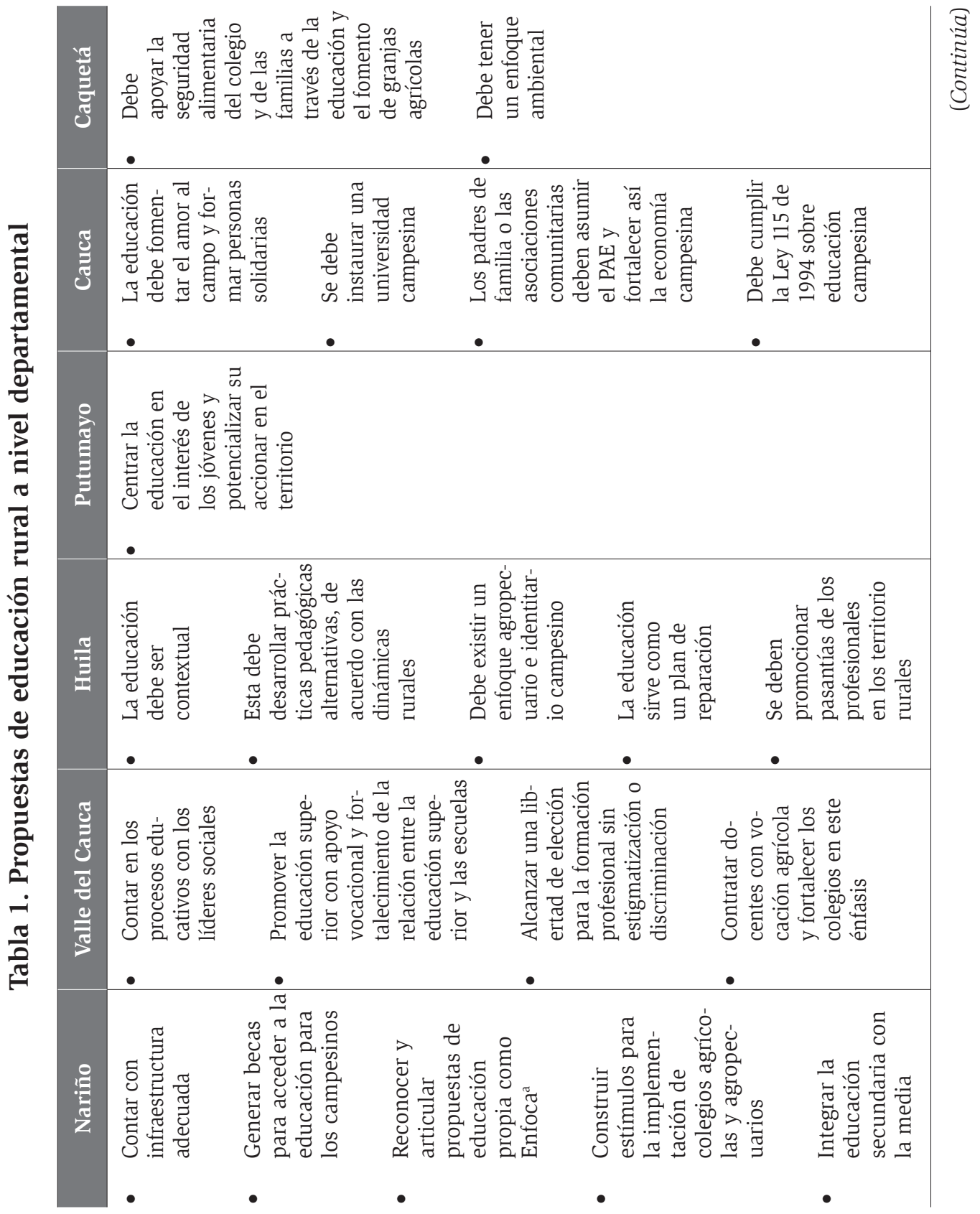




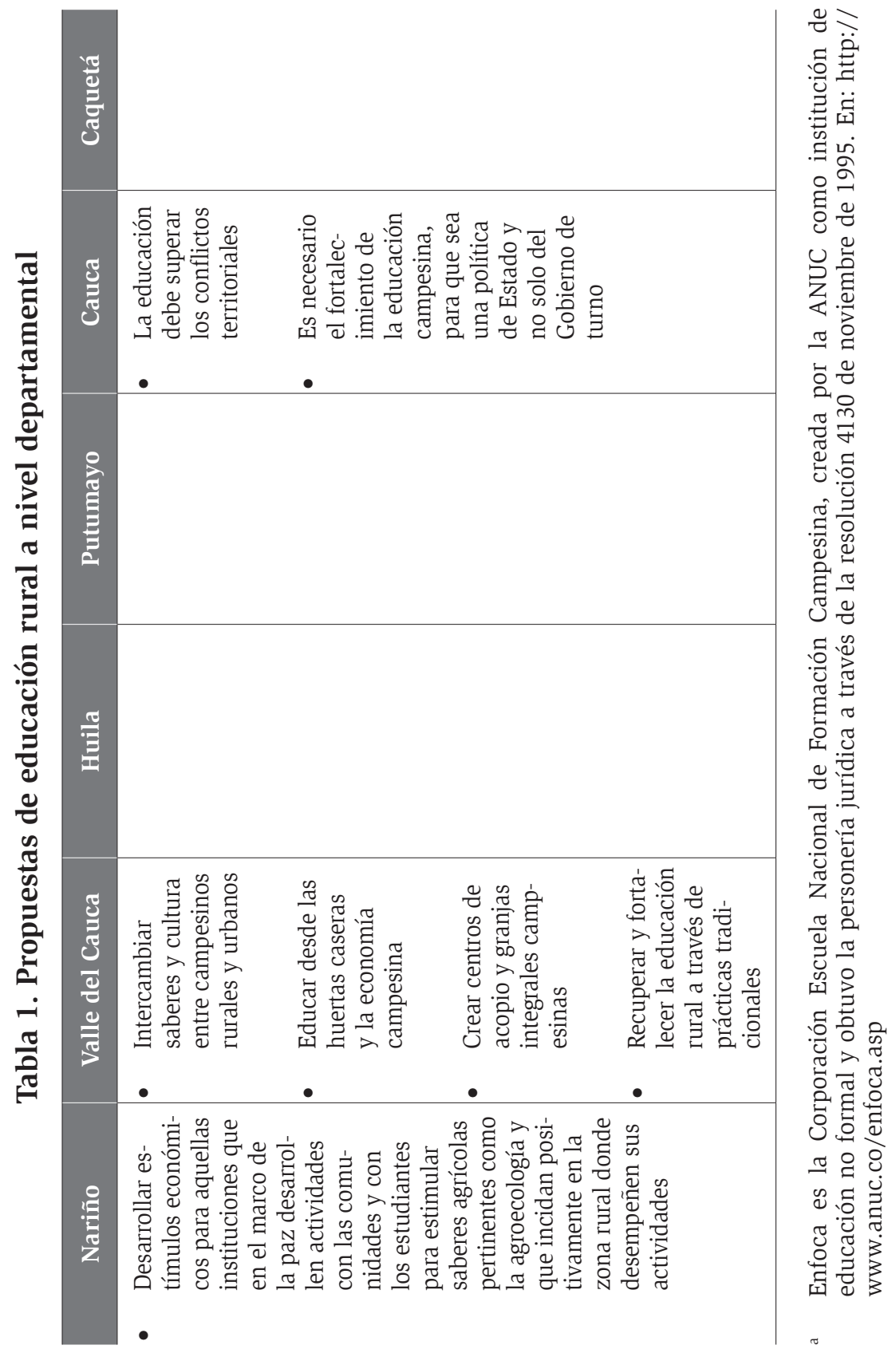


A pesar de que las propuestas responden a particularidades departamentales, es crucial identificar puntos en común, pues con la participación de los campesinos se pueden priorizar estrategias que permitan establecer acciones reales y contundentes para que la educación rural cumpla su objetivo central: superar brechas, potencializar capacidades y consolidar acciones para el desarrollo rural. Es importante destacar la presencia de espacios autónomos de formación dentro de las comunidades y organizaciones campesinas, lo que en principio equivale a la necesidad de armonizar las propuestas de educación formal, no formal y propia.

Es claro el llamado a que la educación transforme la situación de violencia armada y social que viven aún los pobladores de los sectores rurales, por lo tanto, el principio de interculturalidad potencializado desde el educador y el educando permitirá gestionar conflictos, construir puentes de diálogo y, con ello, rastrear estrategias para el acceso, cobertura y permanencia dentro del sistema educativo.

En vista de la relevancia que adquiere la relación entre las comunidades campesinas y la economía campesina, un elemento central en esta educación rural debe ser el otorgamiento de herramientas reales para la producción, comercialización e intercambio de los productos del sector agrario - incluido el intercambio de semillas - , la agricultura llevada a cabo por las familias y la agroecología. Esto da cuenta de que la educación para la paz es posible en tanto se reconozcan las particularidades y contextos de los actores rurales, lo que sin duda debe potencializar el reconocimiento del campesinado como sujeto político y de derechos en el país.

Dado que en el proceso de la implementación de los acuerdos de paz la participación de las comunidades campesinas en relación con la educación rural debe ser real, en el marco de la Estrategia de Fortalecimiento Organizativo, la Mesa Campesina del Cauca CIMA-CNA/PUPSOC-Fensuagro adelantó un borrador de política pública respecto a la educación 
campesina en pro del reconocimiento del campesinado como sujeto de derechos. El objeto de este proyecto - a presentar a la Gobernación del Cauca en una mesa técnica que consolidaron para adelantar acciones que fortalezcan la educación campesina - es identificar contenidos en la normatividad enfocados hacia un reconocimiento multidimensional del campesinado, a través de los cuales se puedan validar las experiencias autónomas de política y mandatos populares en educaciónformación campesina/comunitaria. Estos deben servir de base para la interlocución/negociación con instituciones oficiales a nivel nacional y regional en el marco de la Mesa Campesina del Cauca.

Este documento propone los siguientes elementos para ser tenidos en cuenta en el marco de la propuesta de educación campesina:

Debe ser una política del Estado, no solo de Gobierno, humanización de la educación, enfoque territorial, educación campesina autónoma, conocimiento propio de saberes ancestrales y culturales, emprendimiento e innovación, soberanía alimentaria, producción campesina y técnicas propias, asumir el trabajo campesino como acción pedagógica y la finca como espacio formativo, cátedra campesina basada en la normatividad, derechos campesinos para estudiantes y padres de familia, ordenar la construcción y financiación del Proyecto Institucional Educativo Campesino y territorial campesino, recuperar y promover los principios y valores campesinos frente a otras culturas o consumos, ampliación de cobertura e infraestructura en el territorio, acceso gratuito a la educación superior, exigir pruebas de acceso a educación superior y de calidad diferencial a estudiantes y docentes, formación académica, experiencias y acreditación comunitaria y, finalmente, aprovechar las condiciones del entorno como formación fuera del aula. (Mesa Campesina del Cauca, 2018)

En consecuencia, frente al debate de la educación para la paz, a continuación, se presentan ocho líneas de acción que no solo pretenden pensar la institucionalidad desde el sector público, sino desde las comunidades e instituciones que estén convencidas de que la educación 
es un paso fundamental para la construcción de paz. Por lo tanto, estas líneas se relacionan y presentan una solución al problema de la educación, que expresa que no basta el simple arreglo de la infraestructura o el nombramiento de más docentes o que más gente ingrese al Sistema de Educación Nacional, sino que se espera alcanzar una verdadera articulación de la situación, del contexto y de las vocaciones, aspiraciones y apuestas de las comunidades campesinas.

\section{Estudio nacional con enfoque territorial y participativo sobre la educación rural}

En primer lugar, como orientación estatal es crucial adelantar un estudio con enfoque territorial y participativo sobre la situación de la educación rural en cada uno de los departamentos, con el fin de ubicar el diagnóstico, caracterización y propuestas que se vienen desarrollando por parte de las comunidades rurales, indígenas, afrocolombianas y campesinas. Esto permitirá el fortalecimiento del Sistema Nacional de Educación y la construcción de una política pública de educación rural y de los lineamientos necesarios para superar la inequidad en el acceso a la educación, mejorar la calidad, fomentar la permanencia y constituir a las comunidades rurales como agentes centrales de la educación en sus territorios.

\section{Articulación de la nueva institucionalidad para la paz}

Como lo evidenció la Misión para la Transformación del Campo (2014), el reto para la educación rural es el "diseño de una institucionalidad pública clara al interior del MEN que permita dar los lineamientos y hacer el monitoreo y seguimiento a la política de educación rural es esencial y actualmente” (p. 23). La proyección de acciones efectivas que posibiliten la articulación de la nueva institucionalidad para la paz convoca al Ministerio de Educación, de manera fundamental, y a la Agencia de Renovación Territorial, para que adelanten acciones misionales e institucionales conjuntas que hagan posible la implementación del Plan Especial para la Educación Rural, en el marco del trabajo adelantado en la implementación de los Programas de Desarrollo con Enfoque Territorial. 
Así como los PDET insisten en la construcción participativa de políticas que posibiliten el desarrollo rural, el PEER, para el caso de la educación en el ámbito rural, deberá responder a la pregunta de cómo podrán ser territorializadas y contextualizadas, al tener en cuenta la diversidad de actores, etnias y culturas que habitan los territorios rurales.

\section{Educación intercultural}

La interculturalidad en la educación

va más allá del mero contacto e intersección de los pueblos, y se plantea como una postura no solo ética, sino también política [...]. Se centra en la calidad del proceso de interrelación y encuentro entre distintos [...]. Las relaciones interculturales son complejas, implican negociaciones e intercambios culturales, en los cuales no existe la supremacía de una visión del mundo sobre otra. (Rodríguez, 2017, p. 55)

De esta manera, la educación con enfoque intercultural permite reconocer la diversidad de actores que conviven en el territorio, construir programas educativos integrales que fomenten el diálogo y consolidar canales de encuentro entre toda la comunidad educativa (estudiantes, profesores, trabajadores, padres de familia y comunidad) y escenarios de participación, empoderamiento y pertinencia educativa.

Cuando se reconoce la diferencia cultural desde la educación, es posible reconocer al campesinado como sujeto de derechos y afianzar un aprendizaje mutuo desde el intercambio de saberes, la reciprocidad de los proyectos comunes, la convivencia, las interacciones sociales equitativas, la comunicación comprensiva, la construcción de confianza desde la aceptación mutua, la potencialización de espacios de diálogo y el fortalecimiento de mecanismos de resolución pacífica de conflictos.

\section{Educación para la reconciliación}

El eje de reconciliación posibilitará la siembra de nuevas posibilidades en los jóvenes y la construcción de estrategias para superar los rastros 
de la violencia armada en los territorios rurales de manera armoniosa y digna. La reconciliación tiene gran influencia en dos ámbitos: el primero de ellos es el privado, la actitud individual que fomenta el diálogo y supera las acciones violentas a modo de postura política abierta al reconocimiento del otro desde su diferencia. El segundo es el público, que permite el fomento de estrategias de justicia comunitarias y reparativas y la indagación por la verdad como mecanismo trascendental para la reconciliación y la no repetición. En razón a estos, la educación debe sufrir un giro contundente, cuyo eje principal sea la construcción de la paz como una apuesta política institucional y comunitaria: si reconciliamos las aulas y las ideas de los jóvenes, dejaremos la guerra y nos enfrentaremos a una nueva generación de paz.

\section{Escuelas arraigadas con pertenencia de las comunidades}

Con base en las propuestas formuladas por las comunidades campesinas es crucial fomentar que las escuelas estén arraigadas a las comunidades, sin olvidar el principio de la pertinencia de la educación en todos sus niveles: esta "debe ser reflejada desde aspectos como la organización de autoridad universitaria, la estructura orgánica, los fines universitarios, hasta los modelos pedagógicos y los procesos administrativos". (Muñoz, 2015, p. 12)

Un ejemplo de esta pertinencia es la posibilidad de que el PAE sea ofrecido desde las comunidades campesinas, mediante la gestión de una inversión local y el fomento de la economía campesina. Cuando los estudiantes se empoderan del proceso formativo y comunitario para la construcción de paz y la superación de las necesidades territoriales, se convierten en el elemento central del proceso formativo. Es necesario destacar la necesidad de planeación de la escuela estructurada por medio de núcleos de desarrollo veredal por asociación de escuelas vecinas, en los que se tenga en cuenta la identidad para construir un proyecto pedagógico común. Por último, este principio permite superar el aula de la escuela como centro único de formación y resalta las dinámicas culturales y sociales en las que se gestan procesos de enseñanza, aprendizaje y conocimiento. 


\section{Docentes del territorio y enseñanza basada en el contexto}

Los docentes tienen un papel fundamental como tejedores en la educación, por este motivo, se debe fomentar su pertenencia a los territorios rurales como gestores de paz y constructores de conocimiento. Si se potencializa la pertenencia al territorio o el conocimiento adecuado de las dinámicas territoriales, sociales, políticas, culturales o económicas, es posible encontrar métodos de enseñanza y aprendizaje centrados en el contexto. Estos métodos dan lugar a la participación de los jóvenes en la construcción del saber desde las prácticas propias culturales: "para motivar la permanencia y el arraigo de los jóvenes en el territorio rural, se requiere articular esfuerzos entre la institucionalidad del Estado, alianzas público-privadas y comunitarias que permitan hacer grandes transformaciones en el ámbito productivo de la agricultura familiar”. (Jiménez, 2017, p. 9).

Es imprescindible que el Estado reconozca el papel fundamental que tienen los docentes en la formación de buenos ciudadanos, respetuosos de la diferencia, empoderados de la tarea de resolver conflictos de una forma democrática y pacífica; para alcanzar este objetivo, se debe invertir un mayor presupuesto y mejorar las garantías contractuales.

\section{Educación y desarrollo rural}

Sin lugar a duda, el papel que tendrá la educación en todos los niveles para el desarrollo rural es fundamental. La potencialización de estrategias de construcción de conocimientos propias fomentará los proyectos económicos, los intercambios regionales, las escuelas propias campesinas, la economía familiar y comunitaria, la protección de semillas, la participación de las mujeres en la construcción de conocimiento, las estrategias ambientales sostenibles y la lectura contextual, a fin de superar las necesidades sociales. Las soluciones que se plantean en el marco del primer punto del acuerdo de paz, Reforma Rural Integral, 
están directamente relacionadas con la educación y deben desarrollarse de manera integral: "avanzar en los programas de reforma agraria que favorezcan el acceso a la tierra y la permanencia de ella [...]. Política pública orientada a mejorar la economía familiar campesina y su abastecimiento alimentario, para que se disminuya la deserción escolar". (Jiménez, 2017, p. 9)

\section{Educación y enfoque de género}

Si las cifras generales respecto a la educación rural parecen problemáticas, sin duda alguna, es porque se debe adelantar un proyecto en torno al acceso y permanencia de las mujeres rurales en la educación, cuya diferencia con los que presentan los hombres son abismales. Este linea-

Figura 3. Infografía Laberinto Educación Rural

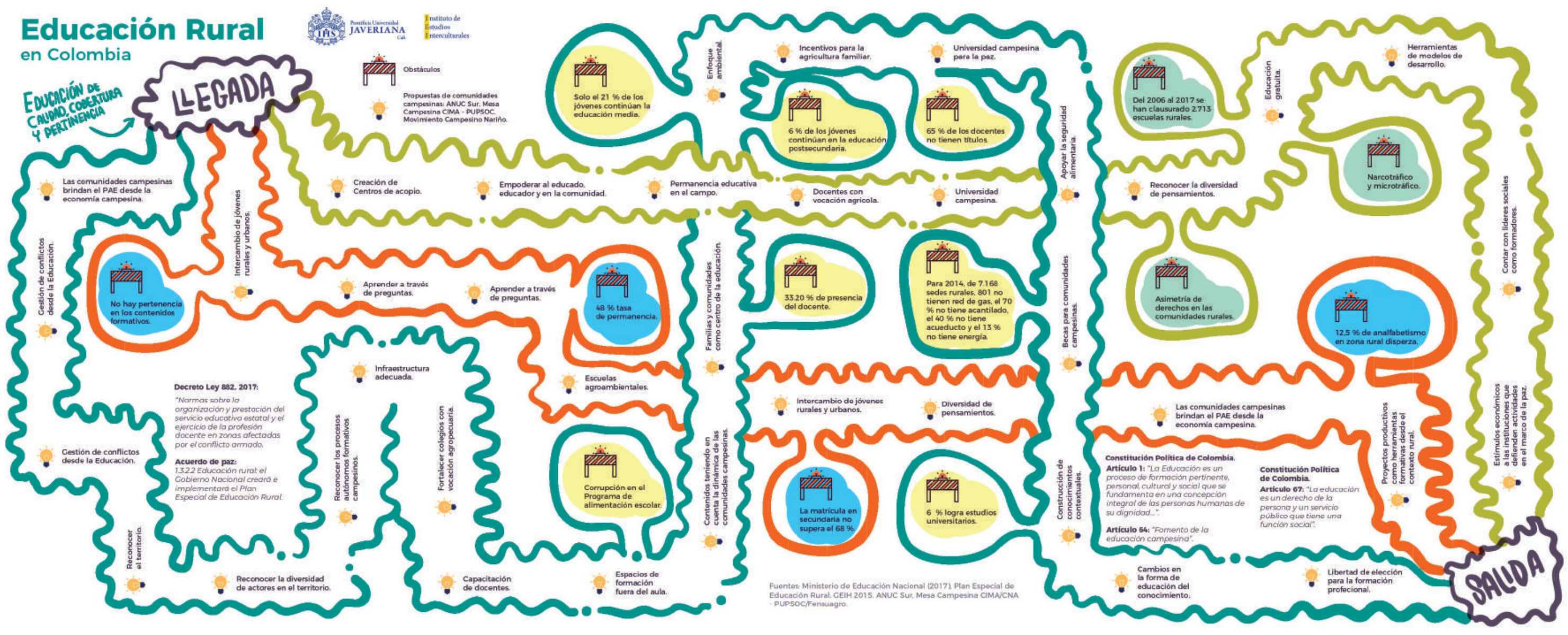


miento invita a preparar escenarios adecuados para la construcción de políticas públicas sobre la educación; asimismo, se debe tener en cuenta la importancia del trabajo y el cuidado de las mujeres rurales, ya que son centrales para el sostenimiento de la economía familiar, enfocada al fortalecimiento de la soberanía alimentaria. En esta medida, la huerta casera, generalmente manejada por las mujeres, se convierte en un lugar privilegiado para la educación inicial campesina:

Así, el cuidado refiere a los bienes y actividades que permiten a las personas alimentarse, educarse, estar sanas y vivir en un hábitat propicio. Abarca por tanto al cuidado material que implica un trabajo, al cuidado económico que implica un costo y al cuidado psicológico que implica un vínculo afectivo. (Batthyany, 2004)

Como resultado del proceso de diagnóstico y propuestas de la educación rural campesina, se construyó, junto con las organizaciones campesinas, la siguiente infografía, que posibilita desde el juego y la creación colectiva la indagación sobre la normatividad, los problemas y propuestas de la educación rural. Será este, por lo tanto, otro insumo para la construcción de propuestas que permitam transformar la educación en una herramienta central para la construcción de paz.

\section{Conclusiones}

Las líneas de acción presentadas en los puntos anteriores evidencian temas que deben ser considerados para comprender la integralidad del problema de la educación en los contextos rurales. La construcción de paz se relaciona con cada uno de estos puntos y consiente la posibilidad de repensar estrategias para que, en efecto, la reconciliación sea posible en los territorios rurales. Por supuesto que estos esfuerzos no son solamente comunitarios, sino que se deben centrar en la voluntad política de las instituciones estatales y gubernamental, para que tenga cabida el planteamiento de una educación para la paz.

Con este propósito, es fundamental, a nivel nacional, departamental y local, adelantar diagnósticos institucionales y comunitarios sobre la 
situación de la educación rural en cada uno de los contextos rurales del país, a fin de reconocer que la superación del problema de la educación vendrá, toda vez que sea posible proponer un sistema educativo que permita la complementariedad en los esfuerzos institucionales y los planteamientos de las comunidades campesinas o rurales. Este panorama debe ir acompañado de cifras, experiencias exitosas y el registro de los espacios de formación propios de las comunidades rurales.

Esto permitirá que la educación sea un tema de interés público, en la medida en que se basa en la capacidad de agenciamiento de las comunidades rurales para incidir y decidir en las políticas públicas que influyen en su territorio. En este sentido, es fundamental comprender que estas dinámicas se enmarcan en apuestas políticas que permiten ordenar el territorio y reconocerlo a partir de la territorialidad de dichas comunidades, que sin duda ofrecen elementos para poder hablar de un desarrollo rural integral.

En consecuencia, la educación como elemento central se relaciona con las dinámicas propias de cada territorio, debe aportar para que las personas puedan vivir con calidad y dignidad y evitar la migración de los pobladores rurales a los centros urbanos. Para tal fin, es imperativo comprender la interculturalidad, encausada a la superación de los conflictos territoriales asociados al reconocimiento de la "otredad" étnica, y situarse en la diversidad cultural. Así, la educación parte de la reconciliación como motor central para que las diferencias sean gestionadas mediante el diálogo y no mediante un fúsil. Finalmente, el enfoque de género generará la posibilidad de hablar de la mujer como elemento central en la educación rural, solo de esta manera podremos evidenciar el aporte que conlleva la educación para la paz en el desarrollo rural.

\section{Bibliografía}

Alto Comisionado para la Paz (2016). Acuerdo Final para la Terminación del Conflicto y la Construcción de una Paz Estable y Duradera.

Atencio, Alfonso (2018). El Decreto 2105 de 2017 y la jornada única. Las2Orillas. Artículo. Recuperado de: https://bit.ly/2OVJcMV. 
Benito, Cynthia (2015). Campesinos frente a indígenas, el otro conflicto colombiano. El Espectador. Artículo. Recuperado de: https://bit.ly/2Q4ht9g

Cárdenas, Santiago (2018). El mapa de los 311 líderes asesinados en Colombia. El Colombiano. Recuperado de: https://bit.ly/2zbajvS

Cinep (2017). Se instala la Mesa Nacional de Educación Rural. Recuperado de: https://bit.ly/2zgExKK

Colombia Renace (2017). Posconflicto. ¿Qué es un PDET? Recuperado de: http:// especiales.presidencia.gov.co/Documents/20170718-pdet/que-son-pdet.html

Consejo Regional Indígena del Cauca (2016). ¡En el territorio de Convivencia y Paz de Lerma, municipio de Bolívar, iDepartamento del Cauca como todo el país colombiano, exigimos que pare la guerra! Recuperado de: https:// bit.ly/2OVLwUn.

DANE (2015). Análisis de la estructura y composición de las principales variables demográficas y socioeconómicas del Censo 2005. Informe final. Recuperado de: https://bit.ly/2OT15Mi

DANE (2014). Condiciones de vida de la población residente en el área rural dispersa censada. Recuperado de: https://bit.ly/2D8u3l2

DANE (2014). Gran Encuesta Integral de Hogares, GEIH. Recuperado de: https:// bit.ly/2Q2bnWV

DANE (2016). 3er Censo Nacional Agropecuario. Hay campo para todos. Tomo 2. Recuperado de: https://bit.ly/2yGIMQr

Díaz, Hernán (2017) 7 postulados de educación para la paz. Siete postulados de Gabo en la búsqueda de un nuevo modelo educativo que explote los talentos innatos de los niños. Centro Gabo. Recuperado de: https://bit.ly/2Sqewl4

Duarte, Carlos (2017). Los conflictos territoriales y la urgencia de una jurisdicción agraria. La Silla Vacía. Red Rural. Recuperado de: https://bit. ly/2P0ldwl

El Nuevo Liberal (2018). El programa PDET. Recuperado de: https://bit.ly/2Sr7pJ3

Jiménez, Myriam (2017). Aportes comunitarios para definir una política de Educación Rural. "para escucharnos y hacernos escuchar desde la ruralidad". Audiencia pública. Educaciones rurales en Colombia. Recuperado de: ht https://docplayer.es/98604305-Aportes-comunitarios-para-definiruna-politica-de-educacion-rural-para-escucharnos-y-hacernos-escuchardesde-la-ruralidad.html. 
Mesa Campesina del Cauca, CIMA-CNA/PUPSOC-FENSUAGRO (2018). Lineamientos de política pública para el reconocimiento del campesinado en el Departamento del Cauca. Base de datos del Instituto de Estudios Interculturales de la Pontificia Universidad Javeriana, Cali.

Ministerio de Educación Nacional (2015). Colombia territorio rural: apuesta por una política educativa para el campo. Recuperado de: https://bit. ly/2PpFDOF

Ministerio de Educación Nacional (2017). Plan Especial de Educación Rural. Hacia un Desarrollo Rural y la Construcción Rural. Recuperado de: https:// bit.ly/2OboTpv

Ministerio de Educación Nacional (2017). Decreto Ley 882 de 2017. Recuperado de: https://bit.ly/2rAAs2z

Ministerio de Educación Nacional (2018). Audiencia pública de educación rural. Recuperado de: https://bit.ly/2CPxM6k

Ministerio de Educación Nacional (2018). Lineamientos para la implementación de la jornada única en Colombia durante el 2018. Recuperado de: https://bit.ly/2IhrRXa

Moreno, Juan (2017). Unos 154 profes fueron amenazados en 2017, en Antioquia. El Tiempo. Recuperado de: https://bit.ly/2AGsrLb

Muñoz, Manuel Ramiro (2015). Educación superior intercultural en Colombia: obstáculos y oportunidades para estudiantes de origen étnico. Tesis de doctorado. Universidad de Barcelona.

Ocampo, José Antonio (2014). Misión para la transformación del campo. Recuperado de: https://bit.ly/2ptNwSv

Oxfam (2016). Desterrados: tierra, poder y desigualdad en América Latina. Resumen Ejecutivo. Recuperado de: https://bit.ly/2ixSXOz

Pardo, Renata (2017). Diagnóstico de la juventud rural en Colombia. Grupo de Diálogo Rural, una estrategia de incidencia. Recuperado de: https://bit. ly/2yNdveT

Pérez, Edelmira y Pérez, Manuel (2002). El sector rural en Colombia y su crisis actual. Red de Revistas Científicas de América Latina y el Caribe, España y Portugal. Artículo. Recuperado de: https://bit.ly/2xIxV8i 
Pérez, Edelmira y Farah, María (2002). Los modelos de desarrollo y las funciones del medio rural en Colombia. Red de Revistas Científicas de América Latina y el Caribe, España y Portugal. Artículo. Recuperado de: https://bit. ly/2Q37DVb

Presidencia de la República. Colombia. ¿Quiénes somos? Recuperado de: https://bit.ly/2mvsRhv

Presidencia de la República. Colombia. Agencia de Renovación del Territorio. Programas de Desarrollo con Enfoque Territorial PDET. Recuperado de: https://bit.ly/2gMjcDj.

Presidencia de la República. Colombia. Pequeñas Infraestructuras Comunitarias PIC. Recuperado de: https://bit.ly/2JoRZ4b

Redacción Judicial (2017). Corrupción en el PAE superaría los \$140 mil millones. El Espectador. Recuperado de: https://bit.ly/2AmkNrY

Rodríguez, Corina (2005). Economía del cuidado y política económica: una aproximación a sus interrelaciones. Versión preliminar. Panel Políticas de protección social, economía del cuidado y equidad de Género. Naciones Unidas-Comisión Económica para América Latina y el Caribe, Cepal. Recuperado de: https://bit.ly/2Ptbn5r

Sánchez, Óscar (2017). Investigar la educación rural. El Tiempo. Recuperado de: https://bit.ly/2vwsE3R

Ruralidad (2017). La transformación rural, cada vez más cerca. Semana. Recuperado de: https://bit.ly/2RgXIeM

Tramas, Parqués Intercultural. Pontificia Universidad Javeriana de Cali. Recuperado de: https://parquesintercultural.wordpress.com/.

Unesco (2004). Educación rural para el desarrollo rural: hacia nuevas respuestas de política. Estudio conjunto realizado entre FAO y Unesco. Recuperado de: https://bit.ly/2JLlnku

Vegas, Emiliana (2016). La educación rural en Colombia: semilla para el desarrollo. Semana. Recuperado de: https://bit.ly/2Su8yiX

Walsh, Catherine (2009). Interculturalidad crítica y educación intercultural. Versión Online. Recuperado de: https://bit.ly/2U2SKrh 